\title{
Sucrose triggers a novel signaling cascade promoting Bacillus subtilis rhizosphere colonization
}

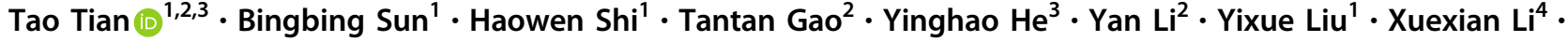 \\ Liqun Zhang ${ }^{2}$. Shidong $\mathrm{Li}^{5} \cdot \mathrm{Qi}$ Wang $\mathbb{D}^{2} \cdot$ Yunrong Chai $\mathbb{D}^{3}$
}

Received: 30 September 2020 / Revised: 2 March 2021 / Accepted: 15 March 2021 / Published online: 26 March 2021

(c) The Author(s) 2021. This article is published with open access

\begin{abstract}
Beneficial rhizobacteria promote plant growth and protect plants against phytopathogens. Effective colonization on plant roots is critical for the rhizobacteria to exert beneficial activities. How bacteria migrate swiftly in the soil of semisolid or solid nature remains unclear. Here we report that sucrose, a disaccharide ubiquitously deployed by photosynthetic plants for fixed carbon transport and storage, and abundantly secreted from plant roots, promotes solid surface motility (SSM) and root colonization by Bacillus subtilis through a previously uncharacterized mechanism. Sucrose induces robust SSM by triggering a signaling cascade, first through extracellular synthesis of polymeric levan, which in turn stimulates strong production of surfactin and hyper-flagellation of the cells. B. subtilis poorly colonizes the roots of Arabidopsis thaliana mutants deficient in root-exudation of sucrose, while exogenously added sucrose selectively shapes the rhizomicrobiome associated with the tomato plant roots, promoting specifically bacilli and pseudomonad. We propose that sucrose activates a signaling cascade to trigger SSM and promote rhizosphere colonization by B. subtilis. Our findings also suggest a practicable approach to boost prevalence of beneficial Bacillus species in plant protection.
\end{abstract}

These authors contributed equally: Tao Tian, Bingbing Sun,

Haowen Shi

Supplementary information The online version contains supplementary material available at https://doi.org/10.1038/s41396021-00966-2.

Tao Tian

tiantao0357@sina.com

$\triangle$ Qi Wang

wangqi@cau.edu.cn

$\triangle$ Yunrong Chai

y.chai@northeastern.edu

1 Institute of Plant Protection, Tianjin Academy of Agricultural Sciences, Tianjin, China

2 Department of Plant Pathology, China Agricultural University, Beijing, China

3 Department of Biology, Northeastern University, Boston, MA, USA

4 Department of Plant Nutrition, China Agricultural University, Beijing, China

5 Institute of Plant Protection, Chinese Academy of Agricultural Sciences, Beijing, China

\section{Introduction}

The soil-dwelling Bacillus subtilis is an excellent biological control agent, capable of suppressing a number of soilborne phytopathogens [1, 2]. Evidence suggests that colonization on plant roots and formation of root-associated biofilms are critical for $B$. subtilis to exert biocontrol activities [3-5]. Rhizosphere, influenced by root-released nutrients, is a relatively eutrophic ecological micro-niches [6-9]. It is well established that plants actively recruit beneficial microorganisms and shape the rhizomicrobiome [6, 10-13]. Considering the relatively large proportion and the diverse and dynamic nature of root exudates among the nutrients released by the plant, root exudates likely play an important role in promoting bacterial root colonization and shaping the rhizomicrobiome $[14,15]$.

As one of the most important biological control agents (BCAs), how B. subtilis overcomes the obstacle of distance to reach the rhizoplane, and establishes beneficial interactions with the roots remains not well understood [16-18]. Chemotaxis, a directed bacterial swimming propelled by flagella in aqueous environments, was shown to play an indispensable role in the colonization of B. subtilis on the Arabidopsis thaliana roots [19,20]. Meanwhile, swarming 
motility was proposed as a more practicable mechanism for the translocation of cells in the natural semiarid soil [21-24]. Swarming on the semisolid surface is characterized by hyper-flagellation of cells and strictly depends on surfactin $[22,25,26]$. Recent studies suggest that swarming plays a critical role in the migration of $B$. subtilis cells to the rhizoplane [27, 28]. Yet environmental signals triggering swarming in B. subtilis are largely unknown [21, 29]. It is worth pointing out that most studies would suggest that $B$. subtilis cells do not swarm on solid surface. An unsettled question thus arising is how $B$. subtilis cells manage to efficiently migrate in the semisolid or solid soil environment $[30,31]$.

We started by investigating root-secreted chemicals that could potentially promote $B$. subtilis root colonization. Here we report that sucrose, a disaccharide deployed by virtually all photosynthetic plants for fixed carbon transport and storage and abundantly released from the roots [32, 33], promotes solid surface motility (SSM) and root colonization by $B$. subtilis through a previously uncharacterized mechanism. Sucrose induces robust SSM of B. subtilis by triggering a signaling cascade via a so-called "levan detour". We further discuss the role of sucrose in establishing symbiosis between $B$. subtilis and plant roots.

\section{Results}

\section{Sucrose promotes root colonization and induces solid surface motility (SSM) by B. subtilis}

We previously revealed that both root-released malic acid and complex polysaccharides from plants induce formation of root-associated biofilms by $B$. subtilis $[4,5]$. Here we investigated the influence of root-released simple sugars (mono- and di-saccharides) on root colonization by B. subtilis. We employed a red fluorescence-labeled B. subtilis strain (YC843, a derivative of the model strain NCIB 3610) to study the influence of selected sugars on bacterial colonization on tomato roots in the sterilized soil. Images from laser scanning confocal microscope (LSCM) suggested more robust root colonization by $B$. subtilis in the presence of sucrose than several other root-secreted sugars (Fig. 1A). Plate recovery counting confirmed that sucrose boosted $B$. subtilis root colonization by about 2.7 -fold compared to no sugar addition, an effect not seen in either glucose, fructose, or maltose (Fig. 1B). To test the possibility that the enhanced root colonization is due to the effect of sucrose on $B$. subtilis growth, we performed assays of growth of B. subtilis cells in two minimal media (MSgg [34] and M9 [35]) as well as LB broth supplemented with either sucrose or any other sugars $(5 \mathrm{~g} / \mathrm{L})$. None of the supplemented sugars, had a significant impact on the growth of
B. subtilis cells while addition of fructose caused a slight reduction in the final cell density of the minimal media cultures (Fig. S1A-C). Thus, our results suggest a previously uncharacterized role of sucrose in promoting root colonization by $B$. subtilis.

When spotted on solid LB agar plates (1.5\% agar, w/v), we noticed that sucrose triggered a robust swarming-like motility in the B. subtilis strain NCIB 3610 (Fig. 1C, hereafter referred to as 3610 ). The velocity of this motility correlated positively with the quantity of supplemented sucrose (Fig. 1C), but negatively with the concentration of agar (Fig. 1D). The maximal speed of the bacterial movement on the solid LB plates supplemented with sucrose $(5 \mathrm{~g} / \mathrm{L})$ is estimated to be $\sim 0.6 \mathrm{~cm} / \mathrm{h}$ at $37{ }^{\circ} \mathrm{C}$ (Fig. 1E). Cells at the outer-edge of the colony presented a hyper-flagellated phenotype (Fig. 1C). This sucrose-induced SSM depends on the flagellar since a flagellar deficient mutant $(\Delta h a g)$ completely failed to perform SSM (Fig. S2A). This SSM was also observed in other Bacillus strains, including B. subtilis (B579, NCD-2, and CAU9407) and B. velezensis (TB1340 and TB1501) (Figs. 1F, S3, Table S1). Interestingly, the observed SSM was less robust in other Bacillus strains than in 3610, indicating that subtle strain differences may have an impact on the intensity of the SSM. Since swarming motility by Bacillus is often studied in semisolid media (0.6-0.7\% agar) [26], this sucrose-induced SSM could represent a novel motility behavior. Alternatively, it suggests that swarming could occur even on solid surface under certain natural circumstances in some Bacillus species. Considering the semisolid or solid nature of soil particles and even the root surface, we suspect that this novel SSM could play a role in the migration of $B$. subtilis cells from bulk soil to rhizosphere and even along the rhizoplane.

\section{Sucrose induces strong surfactin production}

Swarming by $B$. subtilis strictly depends on surfactin production $[22,25,26]$. It was conceivable that sucrose might stimulate strong production of surfactin when triggering SSM. Hence, the influence of sucrose on surfactin production by $B$. subtilis was determined. We performed assays of surfactin production by $B$. subtilis in both LB and the minimal medium MSgg. On solid LB agar plates supplemented with sucrose, cells had an about fourfold increase in surfactin production when compared to cells on just solid LB without sucrose, while other tested sugars (arabinose, fructose, glucose, and maltose) only registered a slight increase in surfactin yield (Fig. 2A). On MSgg agar plates, the overall surfactin yield was modestly lower, yet the addition of sucrose increased surfactin production by more than threefold (Fig. S4B). We next tested if sucrose enhances surfactin production by inducing the srf operon, which encodes the enzyme complex for surfactin synthesis 


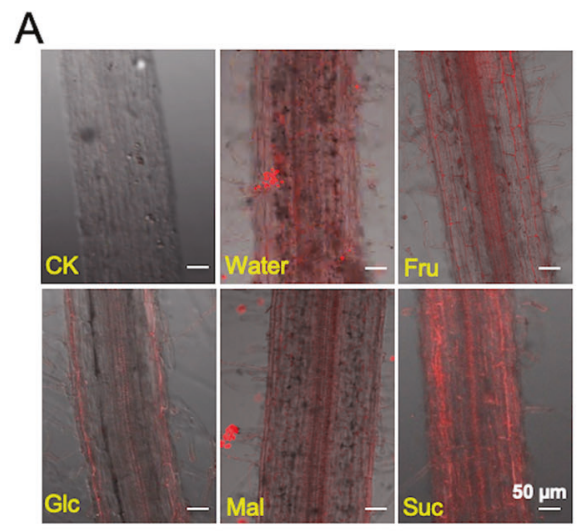

D
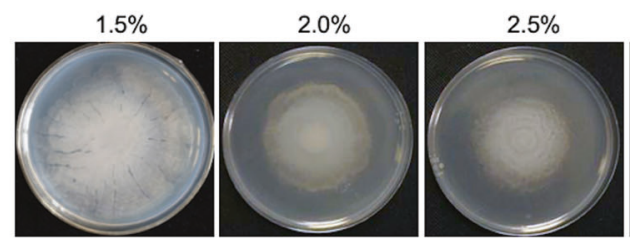

B579

$\mathrm{F}$

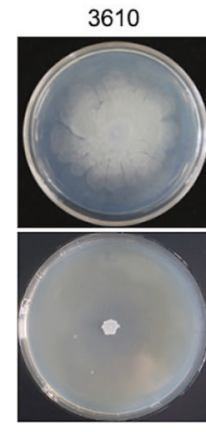

NCD-2

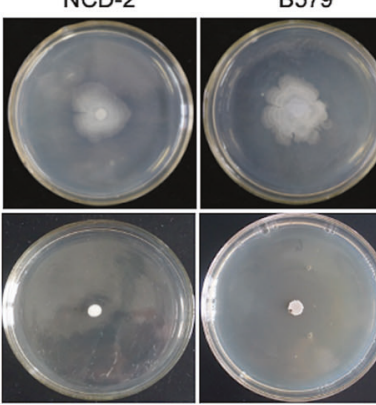

Fig. 1 Sucrose promotes root colonization and solid surface motility (SSM) by B. subtilis. A LSCM images of 18-day-old tomato roots observed $72 \mathrm{~h}$ after inoculation with a $B$. subtilis 3610 derivative constitutively expressing $m$ Kate 2 and treated with different sugars (Fru fructose, Glc glucose, Mal maltose, and Suc sucrose). For treatments of sugars, $5 \mathrm{ml}$ cell suspension supplemented with $0.5 \%(\mathrm{w} / \mathrm{v})$ sugar was applied to the roots. Water indicates the same volume of water replacing any sugar solution. CK indicates no addition of bacterial cells and sugars. Shown pictures are representatives of at least 20 independent root samples (scale bars: $50 \mu \mathrm{m}$ ). B The influence of different sugar supplementations on the colonization of 3610 cells on tomato roots was determined by counting colony forming unit (CFU) per $\mathrm{mm}$ root length. Error bars represent standard deviations. * indicates $p$ value $<0.05$; $* *$ indicates $p$ value $<0.01$; NS no statistical

$[36,37]$. We first employed a reporter strain of 3610 harboring a $g f p$ gene fused to the $s r f$ promoter $\left(\mathrm{P}_{s r f A A^{-}} g f p\right.$, CY106). We collected cells after $4 \mathrm{~h}$ incubation on solid LB plates with or without supplementation of sucrose and examined them under fluorescent microscopy. A much brighter fluorescence was observed for cells harvested from the plates supplemented with sucrose than no sucrose (Fig. 2B). Quantification of the fluorescence signal density indicates about 2.7-fold increase in cells treated with sucrose than without sucrose (Fig. 2C). In another experiment, we compared the activity of the srf operon in the
C

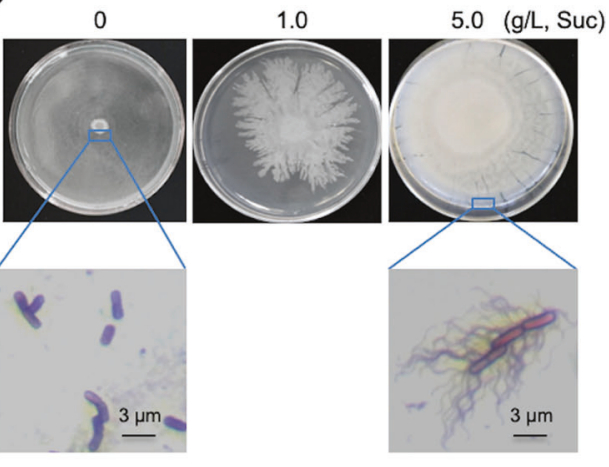

$\mathrm{E}$

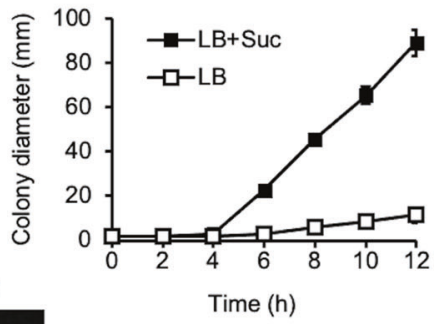

$\mathrm{LB}+$ Suc

$(5 \mathrm{~g} / \mathrm{L})$ difference. C The concentration of supplementary sucrose positively correlated with the robustness of solid-surface movement (SSM) by 3610. The microscopic images of outer-edge cells stained with flagella-specific dye, on solid LB plate with or without sucrose $(5 \mathrm{~g} / \mathrm{L})$. Pictures are representatives of at least five independent samples (scale bars: $3 \mu \mathrm{m})$. D The increasing concentrations of agar negatively influenced the robustness of sucrose-induced SSM. E Colony expanding rate of 3610 on solid LB plate with or without supplementary sucrose $(5 \mathrm{~g} / \mathrm{L})$ was determined by measuring the diameter of the colony periodically. Assays were done in triplicate. Error bars represent standard deviations. F Addition of sucrose $(5 \mathrm{~g} / \mathrm{L})$ also triggered SSM by other Bacillus strains on solid LB plates. All Petra dishes shown here have a diameter of $10 \mathrm{~cm}$.

presence or absence of sucrose by using a $B$. subtilis strain bearing the $\mathrm{P}_{s r f A A}$-lacZ reporter (KG203). We performed assays of $\beta$-galactosidase activities on cells similarly collected from solid LB plates without or with sucrose supplementation, or with supplementation of glucose $(5 \mathrm{~g} / \mathrm{L})$. Addition of sucrose stimulated the activity of the $\mathrm{P}_{s r f A A}-l a c Z$ reporter by about 5.9-fold (Fig. 2D), consistent with the above results from the $\mathrm{P}_{s r f A A^{-}} g f p$ reporter (Fig. 2C). Addition of glucose also stimulated the reporter activity, albeit at a much milder level (Fig. 2D), which could be due to altered metabolic regulation by glucose. Our results indicate that 

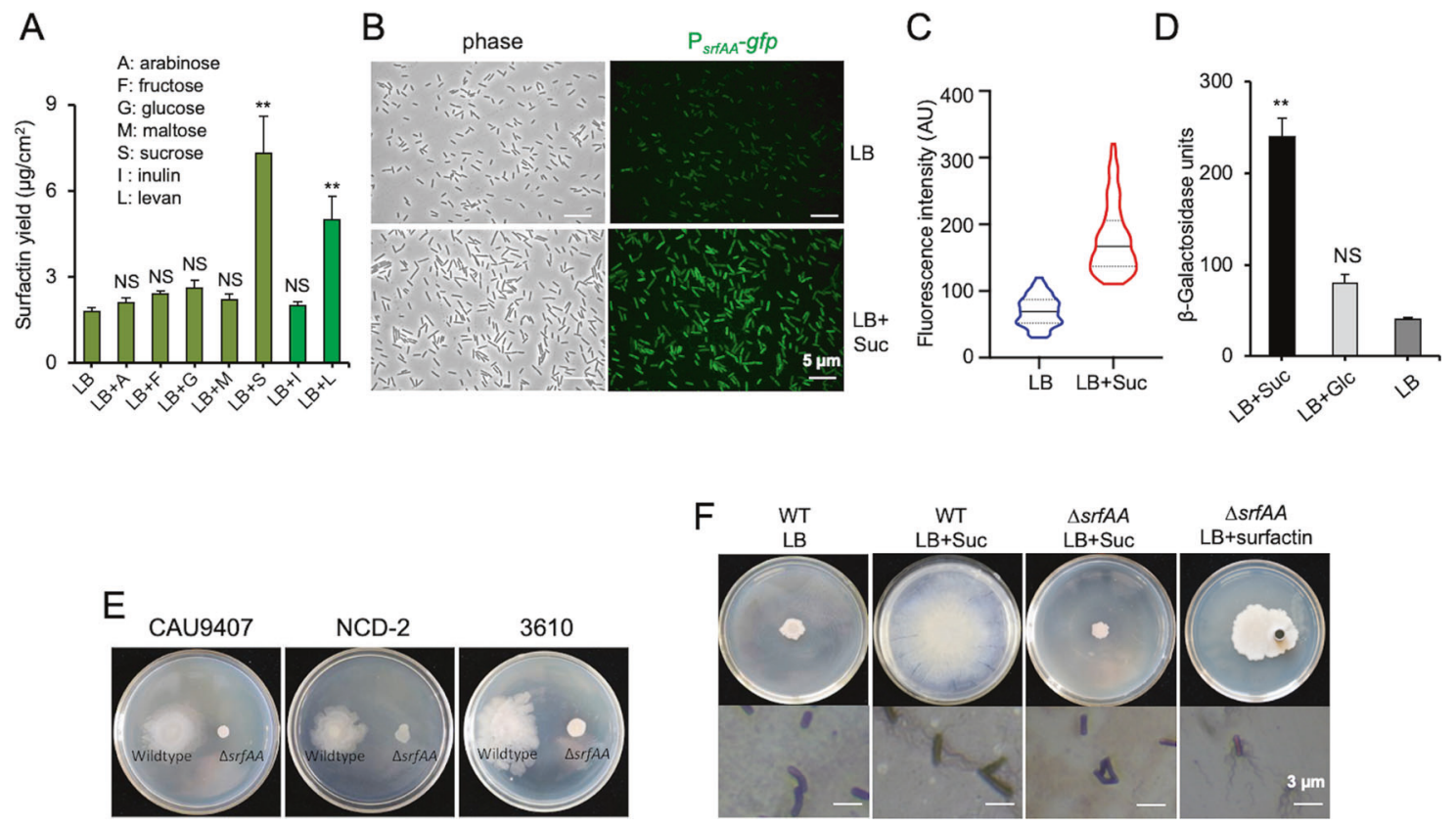

Fig. 2 Surfactin mediates sucrose-induced SSM by $B$. subtilis. A The effect of various sugars on surfactin yield $\left(\mu \mathrm{g} / \mathrm{cm}^{2}\right)$ by B. subtilis 3610 cells was assayed on solid LB agar plates (1.5\% agar, w/v). Samples were collected from the plates supplemented with different sugars, all at the concentration of $5 \mathrm{~g} / \mathrm{L}$. Surfactin was extracted, and the amount of surfactin was determined by HPLC as described in the method. The error bars represent standard deviations from triplicate assays. * indicates $p$ value $<0.05$; ** indicates $p$ value $<0.01$; NS no statistical difference. B Microscopy images of cells harboring the promoter fusion $\left(\mathrm{P}_{s r f A A^{-}} g f p, \mathrm{CY} 106\right)$ collected from the edge of the colonies after $4 \mathrm{~h}$ of inoculation on solid LB plates with or without $5 \mathrm{~g} / \mathrm{L}$ sucrose (scale bars: $5 \mu \mathrm{m}$ ). C Quantification of fluorescence intensity of the cells expressing $\mathrm{P}_{s r f A A^{-}} g f p$ from above. The quantification for each sample is based on roughly 200 cells by using ImageJ. Solid lines in the middle indicates the mean value (artificial units, AU) of the fluorescence intensity. Upper and lower dotted lines indicate the

$75 \%$ and $25 \%$ quartile, respectively. D Assays of $\beta$-galactosidase activities of cells bearing the $\mathrm{P}_{s r f A A}-l a c Z$ promoter fusion (KG203). Cells were similarly collected from the edge of the colonies after $4 \mathrm{~h}$ inoculation from solid LB agar plates without sugar addition, with the addition of $5 \mathrm{~g} / \mathrm{L}$ sucrose or glucose. Assays were done in biological triplicates. Error bars represent standard deviations. ** indicates $p$ value $<0.01$; NS, no statistical difference. $\mathbf{E}$ The $\operatorname{srfAA}$ mutants of three B. subtilis strains (9407, NCD-2, and 3610) lost SSM on solid LB with $5 \mathrm{~g} / \mathrm{L}$ sucrose plates when compared to their wild-type counterparts. Images are representatives of at least 3 independent assays. F Pure surfactin, but not sucrose, rescues the phenotype of SSM and hyper-flagellation in a srfAA mutant of 3610 (Tm01). Solutions (in a volume of $100 \mu \mathrm{L}$ ) containing $180 \mu \mathrm{g}$ surfactin were filled into an Oxford-cup, which is $1 \mathrm{~cm}$ away from the inoculating spot with the B. subtilis cells. All Petra dishes shown here have a diameter of $10 \mathrm{~cm}$.

sucrose enhances surfactin production through gene induction.

To confirm phenotypically that sucrose-induced SSM depends on strong surfactin production, we tested the influence of sucrose on a $\triangle$ srfAA mutant of 3610 (Tm01) deficient in surfactin production [38]. The $\triangle s r f A A$ mutant completely lost motility on solid LB plates even with sucrose supplementation (far right-hand, Fig. 2E), as well as the $\triangle$ srfAA mutants of two closely related $B$. subtilis strains (9407 and NCD-2). Interestingly, the loss of SSM and hyper-flagellation phenotype of the $\triangle$ srfAA mutant could be rescued by exogenously supplementing surfactin even in the absence of sucrose (spotted $1 \mathrm{~cm}$ away from the $\triangle s r f A A$ colony on LB, Fig. 2F). These results provide further evidence that sucrose-induced SSM depends on strong surfactin production. Whether surfactin serves solely as a biosurfactant to facilitate surface migration of cells or serves as a signal as well is not known. However, the induction of hyper-flagellation of the $\triangle s r f A A$ cells by surfactin suggests

its potential role as a signal (Fig. 2F). Our result here is also consistent with previous reports that surfactin induces synthesis of flagellar genes in B. subtilis [39] and that sucrose is able to induce surfactin production in a closely related B. amyloliquefaciens strain [40].

\section{Sucrose induces SSM via "a levan detour"}

Sucrose can be taken into the cells via the phosphortransferase system (PTS) encoded by the $s a c P$ gene and hydrolyzed to glucose-6-P and fructose by a sucrose hydrolase encoded by the highly conserved sacA gene in $B$. subtilis [41, 42] (Fig. 3A). However, neither glucose nor fructose induced SSM in 3610 (Fig. S2B). Further, a $\Delta s a c A$ mutant of $3610(\mathrm{Tm} 13)$ retained the ability of SSM upon sucrose induction (Fig. 3B), indicating that the sacA pathway is not involved in the sucrose-induced SSM. Some Bacillus species employ another sucrose utilization pathway, in which a $\operatorname{sac} B$ gene encodes a levansucrase 
A

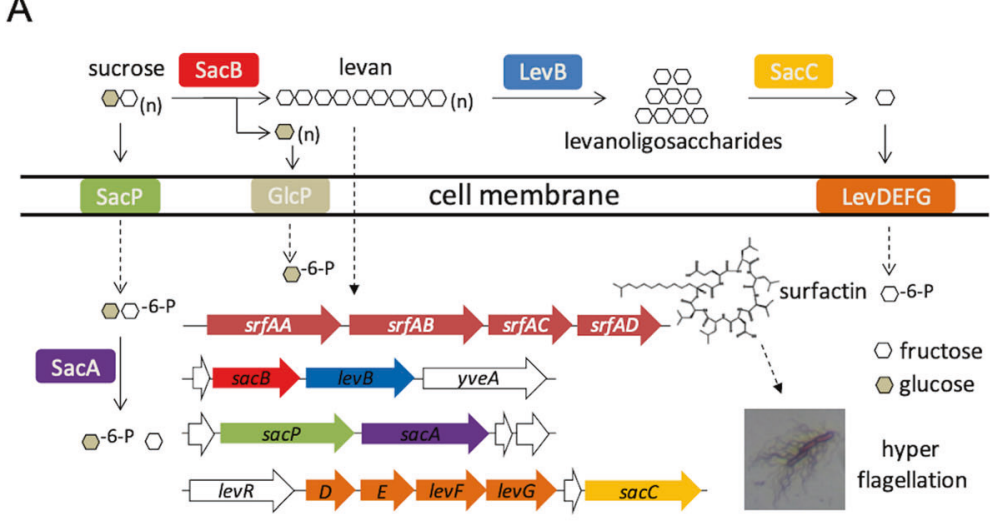

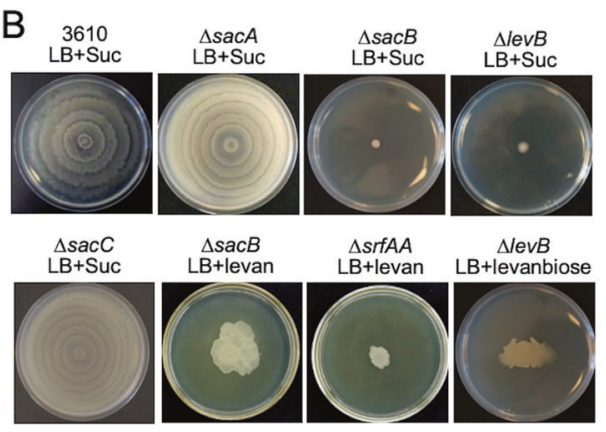

Fig. 3 Levan induces SSM in B. subtilis and other soil bacteria. A A schematic diagram of sucrose metabolism and the signal relay triggering SSM in B. subtilis. On the left of the diagram, it indicates that the extracellular sucrose is imported into cells by the SacP transporter, and then hydrolyzed into glucose-6-P and fructose by the SacA hydrolase. On the top, it illustrates that sucrose is metabolized extracellularly. The levansucrase $\mathrm{SacB}$ uses sucrose to synthesize polymeric fructoses (levan), and glucose. When needed, levan can be degraded into levanoligosaccharides by LevB, and into monomeric fructoses by $\mathrm{SacC}$, which is then imported into cells by the transporter composed of LevDEFG. Levan likely indirectly actives the $\operatorname{srfAA-AD}$ operon, whose product (surfactin) triggers SSM in B. subtilis. B SSM
E
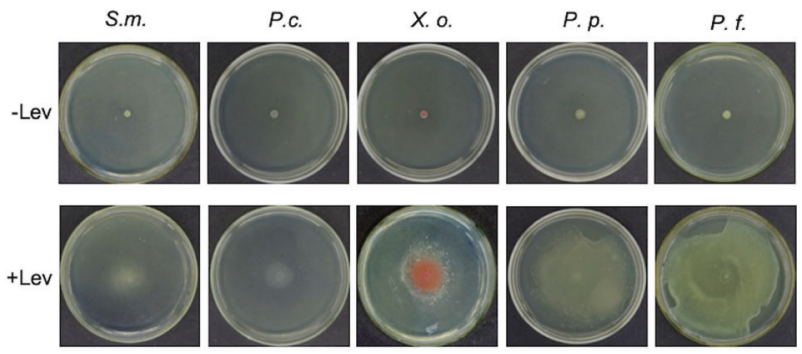

by $B$. subtilis 3610 and various mutants on solid LB plates supplemented with sucrose $(5 \mathrm{~g} / \mathrm{L})$, levan $(0.2 \mathrm{~g} / \mathrm{L})$, or levanbiose $(0.2 \mathrm{~g} / \mathrm{L})$. Pictures are representatives of at least three independent assays. C Pure levan, when supplied at $0.2 \mathrm{~g} / \mathrm{L}$, induces SSM and hyper-flagellation in B. subtilis 3610. D The structural analogues of levan (inulin, FOS, and dextran) cannot induce SSM by B. subtilis 3610 when provided at 0.2 g/L. E Levan $(0.2 \mathrm{~g} / \mathrm{L})$ induces SSM by some soil bacteria (Serratia marcescens T4-3, Pectobacterium carotovorum subsp. carotovorum Z3-3, Xanthomonas oryzae pv. oryzae PXO99F, Pseudomonas protegens $\mathrm{pf}-5$, and $P$. fluorescens $2 \mathrm{p} 24$ ). All pictures are representatives of at least three independent assays. All Petra dishes shown here have a diameter of $10 \mathrm{~cm}$.

plant polysaccharides, including xylose, pectin, and cellulose; none of them showed noticeable inducing effects under the same conditions (Fig. S2C). These results collectively suggested a specific effect of levan in inducing SSM by $B$. subtilis.

We showed earlier that sucrose induces surfactin production (Figs. 2A, S4). To test if the induction is dependent on either one of the two sucrose utilization pathways (SacA or $\mathrm{SacB}$, Fig. 3A), we compared surfactin production by cells of either the WT, or the $\Delta s a c A$, or $\Delta s a c B$ mutant. The assays were performed in both LB and the minimal medium MSgg. Our results suggest that in both media, sucrose largely failed to induce surfactin production in the $\Delta s a c B$ cells, but not the $\Delta s a c A$ cells (Fig. S4A, B). These results reinforced the idea that levan induces surfactin production.

Levan can be further hydrolyzed into levanoligosaccharides by LevB, and into fructoses by SacC (Fig. 3A) [44]. Upon further test, we found that the $\Delta \operatorname{lev} B$ mutant 
(Tm26), but not $\Delta \operatorname{sac} C$ (Tm23), also lost the ability to perform SSM (Fig. 3B), indicating the involvement of levanoligosaccharides in promoting SSM. In support of the above idea, the defective motility of $\Delta l e v B$ can be partially rescued by addition of levanbioses, one of the degradative products of levan by LevB (Fig. 3B). The reason why the rescue effect by levanbioses is less robust than that of levan, we suspect, is because the breakdown products of levan by LevB are likely a mixture of various oligosaccharides including levanbioses [45], and we do not know yet which specific oligosaccharide is most potent in inducing SSM. We rephrased the SacB-LevB pathway as the "levan detour". Previously, the potential metabolic benefit of extracellular production of levan by this $s a c B$ pathway was not as clear as the $s a c A$ pathway. The $s a c B$ pathway is also not as widely present in bacteria as the $\operatorname{sac} A$ pathway.

\section{The "levan detour" confers competitive advantages to $B$. subtilis during root colonization}

Adding sucrose to the soil promoted the colonization of $B$. subtilis on tomato roots (Fig. 1A, B). We wondered if this is due to sucrose inducing SSM by B. subtilis in the rhizosphere via the "levan detour". We thus compared root colonization between the red fluorescence-labeled wild-type strain (YC843), and the "levan detour" mutant $\Delta s a c B$ (Tm32), and $\Delta s a c A(\operatorname{Tm} 31)$, under the pot soil conditions. It was found that the $\Delta s a c B$ mutant, but not the $\Delta s a c A$ mutant, failed to colonize roots effectively as compared to the wild type, even with the addition of sucrose (Fig. 4A, B). Again, addition of sucrose did not impact the growth of either $\Delta s a c A$ or $\Delta s a c B$ cells in either the minimal media (MSgg and M9) or LB media (Fig. S1E, F). These results indicate that not just sucrose, but the "levan detour" is indeed important for root colonization by B. subtilis.

To further support the idea that it is sucrose-induced motility but not sucrose metabolism promoting enhanced root colonization, we repeated tomato plant root colonization experiment in the presence or absence of sucrose using two motility-deficient mutants, $\triangle h a g$ and $\triangle s r f A A$. The $\Delta h a g$ mutant is expected to completely deficient in both swimming and swarming motility due to lack of flagellar while the $\triangle s r f A A$ mutant is known to be deficient in swarming motility, but not swimming and chemotaxis in aqueous environments, due to loss of surfactin production. Our results showed that the $\Delta$ hag mutant was severely impaired in tomato root colonization performed under pot soil conditions even in the presence of sucrose (Fig. S5). The root colonization by the $\triangle s r f A A$ mutant was also clearly impaired both in the presence and absence of sucrose, but surprisingly at a much lesser degree compared to the $\Delta$ hag mutant. This was not entirely unexpected since the $\triangle$ srfAA mutant still retained the ability of swimming and chemotaxis in aqueous environments (such as during initial bacterial inoculation and periodical watering during plant growth).

Lastly, we also tested if sucrose and levan can confer competitive advantages to $B$. subtilis during root colonization by co-inoculating both $B$. subtilis 3610 and $B$. cereus 905 , another soil bacterium that lacks $s a c B$ [46]. In the absence of sucrose, there was only a modest difference in root colonization between 3610 and 905 as judged by CFU counting $(3160+905$, Fig. 4C). Addition of sucrose boosted root colonization by both 3610 and 905 , but the increase was far more substantial in 3610 than in 905 (3610 $+905+\mathrm{S})$. This substantial increase was reversed when the $\Delta s a c B$ mutant of 3610 was co-inoculated with 905 , with or without addition of sucrose; the recovery ratio of 905 : $\triangle s a c B$ was at about 5:1 without sucrose, and up to 10:1 with sucrose supplemented (Fig. 4C). Meanwhile, the $\Delta s a c A$ mutant of 3610 behaved very much like the wild type in the co-colonization experiment $(905+\Delta s a c A$, Fig. 4C). Based on these results, we conclude that the "levan detour" confers significant competitive advantages to $B$. subtilis during root co-colonization.

\section{Plant sucrose secretion is critical for $B$. subtilis root colonization}

More than $20 \%$ of photoassimilates are secreted into the soil by plant roots including a significant proportion of sucrose $[8,47]$. Given the strong influence of exogenously added sucrose on root colonization by 3610 , we reasoned that the endogenous, root-released sucrose could stimulate the colonization of 3610 in planta. In plants, sucrose/proton symporters mediate sucrose allocation towards sink tissues [48, 49]. In Arabidopsis thaliana, SUC2 serves as a predominant transporter in sucrose transport in phloem [48], while SUC3 is the major transporter involved in sucrose exudation from roots [50]. We decided to test root colonization of 3610 in WT and several sugar transport mutants of A. thaliana (Fig. 4D). As shown, B. subtilis had substantially lower root colonization efficiency toward $A$. thaliana $\Delta s u c 2$ and $\Delta$ suc 3 mutants as compared to the wild type (Col-0) and the general monosaccharide transporter mutant STP1 [51, 52] (Fig. 4E, F). Plate recovery counting revealed approximately 6.8- and 8.9-fold decrease in the colonization efficiencies on the $\Delta s u c 2$ and $\Delta s u c 3$ mutants, respectively, compared to the wild type (Fig. 4F). These results support the idea that root exudation of sucrose plays a pivotal role in root colonization by $B$. subtilis.

\section{Sucrose selectively shapes the rhizomicrobiome and enhances disease control}

To investigate if and how root-released sucrose broadly impacts rhizomicrobiome, 16S rRNA gene MiSeq 
A
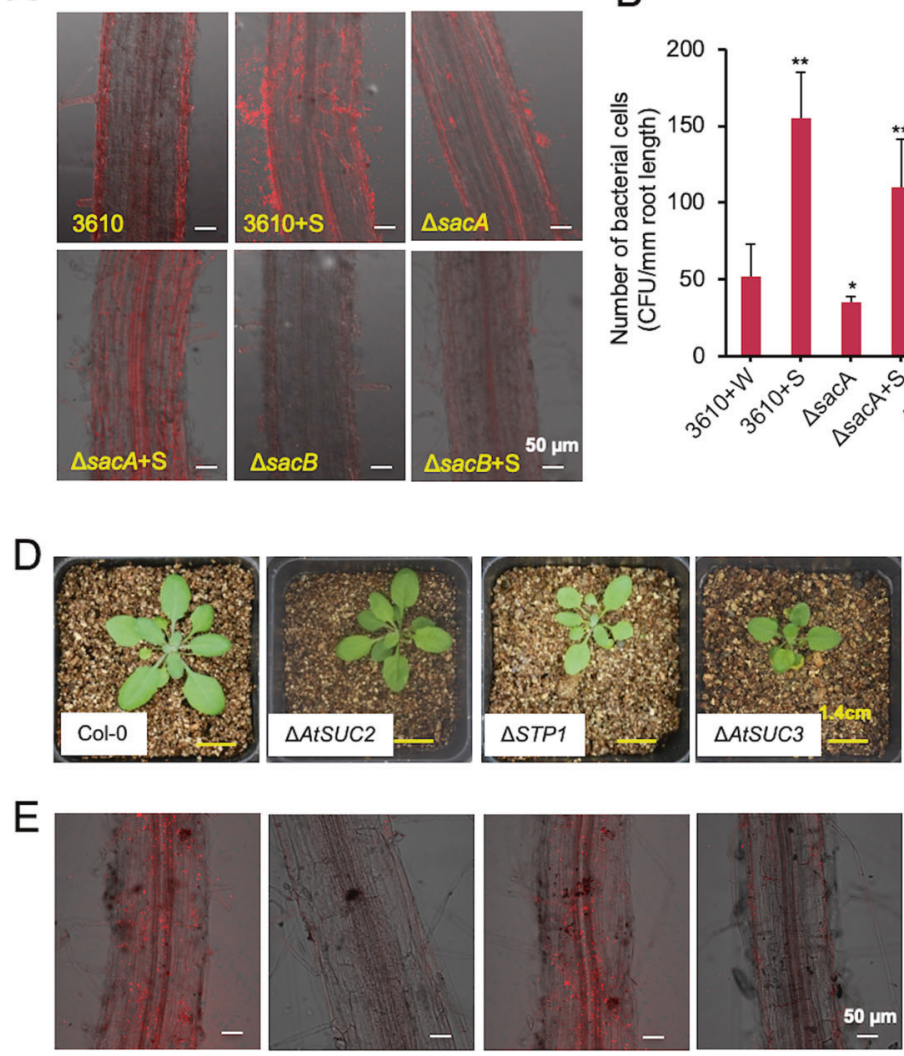

Fig. 4 Sucrose promotes competitive root colonization by $B$. subtilis. A LSCM images of root colonization by WT (3610) and the mutants $(\Delta s a c A$ and $\Delta s a c B)$ treated without or with sucrose $(+\mathrm{S})$. B The difference on the tomato root colonization between the WT and the two mutants was determined by counting colony forming unit (CFU) per mm root length. Error bars represent standard deviations. ** indicates $p$ value $<0.01 ; *$ indicates $p$ value $<0.05$. C The colonization competition between 905 and 3610 (including its derivates) on tomato roots was determined by counting CFU per $\mathrm{mm}$ root length. * indicates $p$ value $<0.05 ; * *$ indicates $p$ value $<0.01$; NS, no statistical difference. D The pictures of seedlings of wild-type A. thaliana (Col-0) and its derivatives impaired in sucrose transport [ $\triangle A t S U C 2$ (At1g22710, SALK_0038124), $\Delta$ AtSTP1 (At1g11260, SALK_048848c), and

sequencing was performed using samples associated with tomato roots pot-grown in natural soil. The microbiome samples were subjected to treatments with or without sucrose supplementation as well as with or without inoculation of B. subtilis (WT or $\Delta s a c B$ ), constituting a total of 6 different treatments (Fig. S6). 16S rRNA gene sequencing of microbiome samples collected 10 days post treatment showed similar overall microbial diversity in all six treatments, indicating a homogeneous complex microbial community (Fig. S6). Out of 50 predominant genus groups for each treatment (Fig. S7), 18 top genus groups were further analyzed (Fig. 5A).

In the rhizosphere soil with only sucrose addition, the relative abundance of Bacillus reached $\sim 10.1 \%$ (CS1-3, Fig. 5A, B), while this ratio was only $\sim 0.1 \%$ without

\section{C}

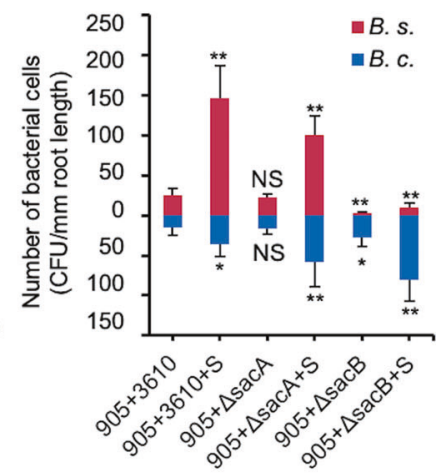

F

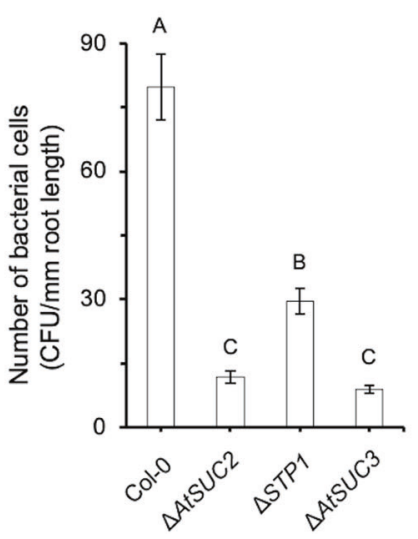

$\Delta$ AtSUC3 (At2g02860, SALK_077723)]. Weakened developmental effects were observed in some of the mutants. Pictures are representative of at least 20 independent plants (Scale bars: $1.4 \mathrm{~cm}$ ). E LSCM pictures of 15-day-old roots of wild-type A. thaliana and the mutants. The roots were observed $72 \mathrm{~h}$ after inoculation with strain 3610 constitutively expressing mKate2. Pictures are representative of at least 20 independent roots (Scale bars: $50 \mu \mathrm{m}$ ). F The influence of different sugar transporters on the colonization of 3610 on the A. thaliana roots was determined using colony forming unit (CFU) per $\mathrm{mm}$ root length by plate recovery counting. The letters above the columns indicate statistically significant differences of different groups based on Student's $t$ test $(p<0.01)$.

sucrose addition (C1-3), indicating a 100-fold increase in the abundance of the native Bacillus species in the rhizosphere stimulated by sucrose. Further inoculation of WT B. subtilis caused no additive effect on Bacillus abundance ( 9.6\%) (AS1-3, Fig. 5A, B), possibly due to the upper limit of Bacillus enrichment in the tomato rhizosphere. Interestingly, when the $\Delta s a c B$ cells were inoculated together with sucrose addition, the abundance of Bacillus genus only reached $6.6 \%$, which was likely contributed by the native Bacillus genus in the soil (BS1-3, Fig. 5A, B). The relative abundance of Bacillus genus was about $0.28 \%$ when the $\Delta s a c B$ cells were inoculated without sucrose (B13, Fig. 5A, B). In summary, our results clearly demonstrated the strong positive influence of sucrose on the increased prevalence of Bacillus genus in the tomato root rhizosphere. 


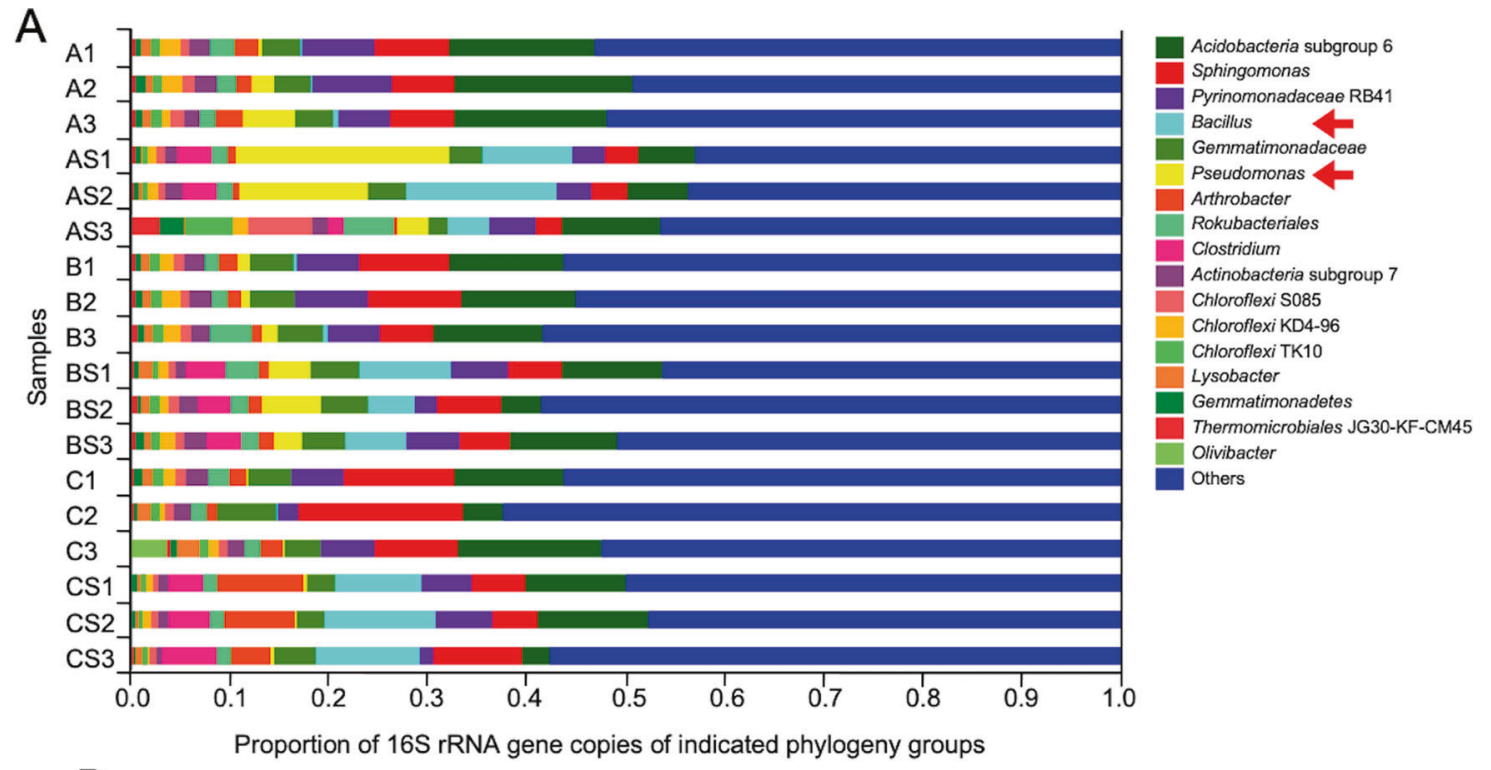

B
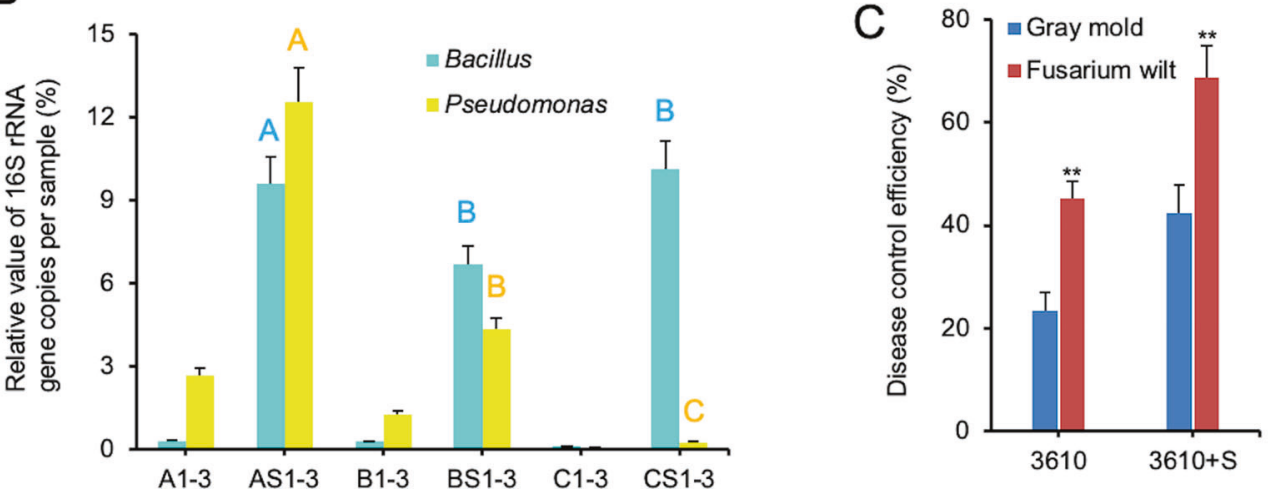

Fig. 5 Sucrose selectively shapes rhizomicrobiome and enhances disease control by $\boldsymbol{B}$. subtilis. A The relative abundance of 18 top genus groups. Community barplot analysis of bacterial taxonomic groups (genus level) in the tomato root rhizosphere with $B$. subtilis 3610 or $\Delta s a c B$, and with or without the addition of sucrose. Different treatments are marked as: A (WT), AS (WT + sucrose), B $(\Delta s a c B)$, BS $(\Delta s a c B+$ sucrose), $\mathrm{C}$ (-sucrose), and CS (+sucrose). The numbers 1-3 represent three repetitions. The 18 different colors represent different bacterial genus. The Bacillus and Pseudomonas groups are highlighted by arrows. B The ratio of Bacillus and Pseudomonas species in the microbiome samples based on the relative value of averaged 16S rRNA gene copies per sample (16S rRNA copies/g soil) in the rhizomicrobiome samples with B. subtilis 3610 or $\Delta s a c B$ mutant

We were somewhat surprised that the initial inoculation of either the wild-type $B$. subtilis or the $\Delta s a c B$ cells did not further increase the overall abundance of Bacillus in the rhizomicrobiome. In addition to strong positive influence of sucrose on the prevalence of Bacillus genus, the relative low abundance of Pseudomonas $(0.05 \%$, C1-3, Fig. 5B) was also elevated to $2.7 \%$ when inoculated with the wild type $B$. subtilis cells (A1-3, Fig. 5B) and further increased to $12.5 \%$ with simultaneous $B$. subtilis inoculation and sucrose supplementation (AS1-3, Fig. 5B). Addition of sucrose alone also elevated the abundance of Pseudomonas, although to a in sucrose and no sucrose conditions. Note: A B. subtilis 3610, AS B. subtilis 3610 plus sucrose, B $\Delta s a c B$ mutant, BS $\Delta s a c B$ mutant plus sucrose, $C$ no 3610 and sucrose, and CS with only sucrose. Values are given as means of three independent biological replicates and the bars represent the standard error. The letters above the columns indicate statistically significant differences based on the 16S rRNA gene copies of Bacillus or Pseudomonas per sample and using the Student's $t$ test $(p<0.01)$. C Combination of sucrose and the B. subtilis improved the biological control efficiency against the soil-borne disease (fusarium wilt) and the resistance to the air-borne disease (gray mold) in tomato. ** indicates $p$ value $<0.01$; NS no statistical difference. The error bars represent standard deviations from triplicate assays.

much lesser degree (from $0.05 \%$ in $\mathrm{C} 1-3$ to $0.27 \%$ in $\mathrm{CS} 1$ 3, Fig. 5B).

Finally, we investigated if addition of sucrose may enhance biological control efficacy by promoting the root colonization and activities of beneficial bacteria such as B. subtilis. Tomato plants were challenged by two distinct pathogenic fungi, Fusarium oxysporum and Botrytis ciner$e a l$, respectively. Biological control experiments were carried out as described in the methods and disease index quantified. Our results showed that supplementation of sucrose to the 3610 formula both improved the suppression 
efficiency against the soil-borne disease caused by Fusarium oxysporum sp. Lycopersici (Fusarium wilt) by $\sim 51 \%$, and enhanced the resistance to the air-borne disease caused by Botrytis cinerea in tomato (gray mold) by about $\sim 80 \%$ compared to no sucrose supplementation formula (Fig. 5C). Our results thus suggest that the direct and indirect effects by plant-released sucrose is likely more profound than simply being a carbon source for bacteria in the rhizosphere.

\section{Levan also induces SSM and hyper-flagellation in other soil bacteria}

Levan was first found in the natto, a traditional Japanese health food fermented by B. subtilis, and was termed as "lävulan" by Lippmann in 1881 and denominated by GreigSmith in 1901 [53, 54]. In addition to B. subtilis, a batch of other bacteria, including the genera of Acetobacter, Erwinia, Gluconobacter, Halomonas, Microbacterium, Pseudomonas, Streptococcus, and Zymomonas, have the sacB gene homologs, which share a common ancestor [44] (Fig. S8). It is possible that some of these $s a c B$-containing bacterial species are also capable of producing levan when associated with plants. We thus wondered if levan could induce SSM in other soil bacteria as well. Our results showed that levan $(0.2 \mathrm{~g} / \mathrm{L})$ can induce SSM and hyper-flagellation in selected rhizospheric bacteria such as Serratia marcescens, Pectobacterium carotovorum, Xanthomonas oryzae, Pseudomonas protegens, etc (Figs. 3E, S9). Again, this inducing effect was specific to levan since inulin, FOS, and dextran did not show any inducing effect (Fig. S9).

\section{Discussion}

Rhizobacteria plays a pivotal role in protecting plants and promoting plant growth and health [2, 10, 17, 55]. How the beneficial bacteria recognize the signals from the plant host, colonize the roots, and ultimately establish an intimate relationship with the plant has been an intensely investigated topic in the field [5, 6, 20, 56-58]. One of the specific focuses is on plant root-released nutrients and their impact on the rhizospheric bacteria [8, 14, 16, 32, 59]. Among those root-released nutrients, sucrose is found most abundantly released into the rhizosphere [32, 60, 61]. Sucrose is uniquely important to the plants since photosynthetic plants primarily use sucrose as a fixed carbon transport and storage mechanism among different tissues [60]. To the bacteria, however, sucrose is often regarded as a common carbon source among many other nutrients released by the roots. Here, we presented evidence for a more comprehensive and unique role of the root-released sucrose in inducing root colonization and promoting rhizosphere prevalence by B. subtilis. Our study also suggests that sucrose may be important as well to those rhizospheric bacteria possessing the $s a c B$ pathway. Sucrose was found to be the most abundant sugar in the soil near the root tip of the annual grass Avena barbata [61]. Sucrose secretion by the plant hosts was shown to be significantly enhanced during various biotic and abiotic attacks [62, 63]. It is plausible that plants may have employed root secretion of sucrose as a general defense mechanism during stress response by selectively enhancing root colonization of sucroseresponsive beneficial bacteria such as B. subtilis. On the other hand, rhizospheric bacteria like Bacillus may have evolved to use sucrose as a unique plant signal that promotes root colonization [64].

Chemotaxis is proposed to play a key role in bacterial root colonization [56]. In a previous study, application of various mutants of $B$. subtilis provided convincing evidence that the function of motility and chemotaxis is key to bacterial root colonization [20]. However, since chemotaxis is perceived as a directed swimming driven by flagella in aqueous environments [65], swimming-driven motility may not fully explain bacteria swiftly migrate in the rhizosphere, considering the semiarid or arid nature of the rhizosphere soil. It is quite possible that soil bacteria oftentimes have to reply on certain types of solid or semisolid surface motility in order to efficiently perform rhizosphere migration. In this study, we characterized solid-surface migration by $B$. subtilis stimulated by sucrose. Sucrose acts as a signal to initiate a signaling cascade leading to biosynthesis of levan and strong production of surfactin. Surfactin may have multiple roles in promoting $B$. subtilis rhizosphere colonization. One, it functions as a biosurfactant to promote surface migration; second, it acts as a signal to stimulate hyperflagellation of $B$. subtilis cells through a yet unknown mechanism; third, surfactin may promote root-associated biofilm formation by $B$. subtilis; [64] fourth, surfactin, as an antimicrobial peptide [36], may help B. subtilis compete with other species in the rhizosphere. Thus, root-released sucrose and the signaling cascade are indeed critical to promote rhizosphere colonization and competition by B. subtilis and other Bacillus species. A previously published study suggested that surfactin is not important in root colonization by $B$. subtilis [66]. We hope to point out that root colonization assays in that study were primarily performed in aqueous media with Arabidopsis roots and the bacterial root colonization was measured by $\mathrm{CFU}$ counting within 24-48 h after B. subtilis inoculation (based on descriptions in the method) [66]. Surfactin is not known to be important in swimming motility and chemotaxis in aqueous environments. In this study, root colonization assays were performed exclusively in pot soil on tomato plant. Therefore, results from both studies could be potentially valid because of very different experimental settings used in root colonization assays. Even so, in our study, in 
the absence of added sucrose, the surfactin mutant only showed an about 1.8-fold reduction in root colonization compared to the wild type (Fig. S5). We speculate that this could be in part due to initial bacterial inoculation and periodical watering during plant growth. These watering events may allow surfactin mutants to perform swimming motility and root colonization to some degree. In other words, the importance of surfactin on B. subtilis root colonization could depend on the environment; a more aqueous environment may diminish the importance of surfactin in root colonization.

In this study, we also revisited the role of levan, identified a century ago and nowadays widely applied in the industries of food, cosmic, and health care [44]. The biological function of levan and the metabolic benefit of such a pathway to the producing bacteria are not clear. Our study suggests that levan acts as one of the chemical signals in the signaling cascade that leads to effective root colonization by B. subtilis. Levan was recently found in the biofilm of B. subtilis [67], which is known to play an important role in establishing symbiotic interactions between $B$. subtilis and the plant. In another published study [68], it was reported that levan can stimulate soil aggregation, which in turn could significantly influence spreading and rhizosphere presence by the soil bacteria. Homologs of the $s a c B$ gene are found in a number of rhizospheric bacteria, and more interestingly, levan can stimulate similar solid-surface movement and hyper-flagellation in other rhizospheric bacteria (Figs. S6, S7). Taken together, these results strongly suggest that the $s a c B$ pathway and levan could play an important, previously less characterized, role in root colonization in other soil bacteria as well. Interestingly, sucrose also showed a mild effect on the root colonization by both the flagellar and surfactin mutants (Fig. S5). We speculate that this could be due to the effect of levan, the polysaccharide made from sucrose, which itself is proposed to have biosurfactant-like activities. It is possible that sucrose may stimulate root colonization through other unknown mechanisms. For example, sucrose may alter metabolic status of the cells (not necessarily the growth rate), which could stimulate root colonization independent on enhancing surfactin production.

Finally, our findings suggest a practicable approach to boost colonization of beneficial Bacillus species and intervene rhizosphere microbiome that promotes the disease control efficacy against some soil-borne phytopathogens $[69,70]$. Application of sucrose may significantly enhance the biological control efficacy of BCAs, which now demonstrate a rising popularity in the agricultural field due to their biosafety and environment friendliness compared to traditional chemical pesticides and fertilizers. The increased disease control efficacy may be due to competitive root colonization, and production of surfactin and other antibiotic compounds by beneficial bacteria such as Bacillus and Pseudomonas species, as discussed in a number of previously published studies $[2,27,36,71]$.

\section{Methods}

\section{Strains and growth media}

Bacterial strains including Bacillus subtilis, their isogenic derivatives, and various other bacterial strains (Table S1) used in this study were routinely grown in Lysogeny Broth (LB). The recipe for the minimal medium MSgg was described previously, in which $0.5 \%(\mathrm{w} / \mathrm{v})$ glycerol is supplied as the carbon source [34]. M9 minimal medium [35] used in this study contained $0.4 \%$ (w/v) glucose as the carbon source prior to supplementation of any other sugars. For assaying SSM, different sugars were supplemented to the solid LB media at the concentration of $5 \mathrm{~g} / \mathrm{L}$ unless specifically indicated. When required, antibiotics were supplemented at the final concentrations as follows for B. subtilis: erythromycin $1 \mu \mathrm{g} / \mathrm{mL}$, tetracycline $5 \mu \mathrm{g} / \mathrm{mL}$, chloramphenicol $20 \mu \mathrm{g} / \mathrm{mL}$, spectinomycin $100 \mu \mathrm{g} / \mathrm{mL}$, and kanamycin $10 \mu \mathrm{g} / \mathrm{mL}$. The pathogenic fungal strains were grown on Potato Dextrose Agar (PDA) media at $25^{\circ} \mathrm{C}$ [72]. Sugars were purchased from Thermo Fisher Scientific (Burlington, MA, USA). Chemicals including surfactin, levan, inulin, FOS, and dextran were purchased from Sigma-Aldrich (St. Louis, MO, USA). Levanbiose was purchased from Megazyme (Megazyme International Ltd., Ireland). Restriction enzymes were purchased from New England Biolabs (Ipswitch, MA, USA).

\section{Strain construction}

The general methods for molecular cloning followed published protocols [35]. Preparation of genomic DNAs from B. subtilis was described previously [73]. Restriction enzymes were used according to the manufacturer's instructions. To construct the insertional deletion mutants in the B. subtilis NCIB 3610 (hereafter abbreviated as 3610), the genomic DNA of the corresponding mutant of the $B$. subtilis 168 strain (obtained from the Bacillus Genetic Stock Center, BGSC) which harbors an antibiotic resistance gene cassette-tagged insertional deletion mutation in the target gene, was prepared and introduced into the B. subtilis 3610 by genetic transformation as previously described [74]. The insertional deletion was verified by PCR amplification of the genomic region and DNA sequencing of the amplified DNA fragment. To construct various reporter strains in the 3610 background, the genomic DNA containing the reporter construct and antibiotic resistance marker were prepared from previously constructed strains (Table S1) and 
introduced into 3610 or its derivatives by genetic transformation.

\section{Tomato root colonization}

The tomato cultivar "Zhongza 9" was procured from the China Vegetable Seed Technology Co., LTD (Beijing, China). The tomato seeds were surface sterilized by a $60 \mathrm{~s}$ soak in $75 \%(\mathrm{v} / \mathrm{v})$ ethanol, followed by $5 \mathrm{~min}$ in sodium hypochloride solution (10\% active chlorine), and by three subsequent wash steps with sterile water for $10 \mathrm{~min}$ each. Sanitized tomato seeds were deposited into the petri dish ( $10 \mathrm{~cm}$ in diameter), which was covered by a sterilized filter paper and contained $1 \mathrm{~mL}$ of sterilized water. The petri dish was incubated in moisture chambers at $28^{\circ} \mathrm{C}$ for $48 \mathrm{~h}$. When seeds started to germinate, the seeds were transplanted to plastic pots $(70 \mathrm{~mm} \times 70 \mathrm{~mm} \times 75 \mathrm{~mm})$ containing $15 \mathrm{~g}$ sterilized vermiculites, and the pots were incubated in moisture chambers $\left(28^{\circ} \mathrm{C} / 20^{\circ} \mathrm{C}\right.$ day/night temperatures, $3500 \mathrm{Lux}$ light for $16 \mathrm{~h} / \mathrm{d}$, and $70 \%$ relative humidity). The pots were watered weekly with nutrient solution. After 15 days of incubation, $5 \mathrm{~mL}$ cell suspension containing freshly cultivated $B$. subtilis cells $\left(1.0 \times 10^{8} \mathrm{CFU} / \mathrm{mL}\right)$ and supplemented with different sugars $(5 \mathrm{~g} / \mathrm{L})$ was added to the pot by pouring it to the root surrounding. After another 3 days of incubation, roots of seedling were taken out and rinsed with sterilized water; $1 \mathrm{~cm}$ root ripening zone for each sample was then collected and quickly stored in the sterile Eppendorf tube for LSCM and plate recovery counting.

\section{Arabidopsis thaliana root colonization}

Seeds of the A. thaliana mutants $\triangle S T P 1$ (SALK-048848C), $\triangle A t S U C 2$ (SALK-038124), and $\triangle A t S U C 3$ (SALK-077723) were obtained from Arabidopsis Biological Resource Center (The Ohio State University, USA). The wild-type A. thaliana used in this study is Col-0 (a kind gift from Dr. Pengmin Zhou, China Agricultural University, Beijing, China). The A. thaliana seeds were surface sterilized by a $30 \mathrm{~s}$ soak in $75 \%$ (v/v) ethanol, followed by $5 \mathrm{~min}$ in sodium hypochloride (10\% active chlorine) and by three subsequent wash steps with sterile water for at least $10 \mathrm{~min}$ each. Sterilized seeds were then transferred onto the $0.7 \%$ Murashige and Skoog agar plate and cold-incubated at $4{ }^{\circ} \mathrm{C}$ and dark for 3 days for optimal germination. The plates were then incubated in moisture chambers at $22^{\circ} \mathrm{C}$ for 3 days until the length of the $A$. thaliana roots reached about $1 \mathrm{~cm}$. The seedlings were transplanted to the plastic pots $(70 \mathrm{~mm} \times 70 \mathrm{~mm} \times 75 \mathrm{~mm})$ containing $15 \mathrm{~g}$ sterilized vermiculites, with an initial moisture content of $100 \%(\mathrm{v} / \mathrm{w})$ and incubated in moisture chambers $\left(22^{\circ} \mathrm{C} / 22^{\circ} \mathrm{C}\right.$ day/night temperatures, 3000 Lux light for $16 \mathrm{~h} / \mathrm{d}$, and $60 \%$ relative humidity), and watered weekly with nutrient solution. After 20 days of incubation, $5 \mathrm{~mL}$ overnight cultivated cell suspension of $B$. subtilis $\left(1.0 \times 10^{8} \mathrm{CFU} / \mathrm{mL}\right)$, supplemented with different sugars $(5 \mathrm{~g} / \mathrm{L})$, was inoculated by pouring to the root. After another 3 days of incubation, roots of seedlings were taken out and rinsed with sterilized water; then $1 \mathrm{~cm}$ root ripening zone for each sample was taken and quickly stored in the sterile Eppendorf tube for Laser confocal microscopic imaging and cell recovery counting.

\section{Cell recovery counting}

One milliliter of sterile water was added to the Eppendorf tube containing $1 \mathrm{~cm}$ preprocessed root and vortexed for $10 \mathrm{~min}$. The suspension was serially diluted with distilled water. $100 \mu \mathrm{L}$ cell suspension from various dilutions $\left(10^{-2}, 10^{-3}\right.$, or $\left.10^{-4}\right)$ was plated onto LB plates supplemented with the appropriate antibiotic. Plates were incubated overnight at $35^{\circ} \mathrm{C}$. The number of colony forming unites (CFU) per mm root was determined. The experiment was repeated three times with ten root samples per replicate.

\section{Biological control}

Seeds of the tomato cultivar "Zhongza 9" were pregerminated as described above, and each germinated seedling was sowed into a plug of the nursery tray that contained dry sterilized artificial mixed soil (vermiculite: turf: soil = $1: 1: 1, \mathrm{v} / \mathrm{v})$. After $20 \mathrm{~d}$ of cultivation, seedlings were transplanted into plastic pots $(70 \mathrm{~mm} \times 70 \mathrm{~mm} \times 75 \mathrm{~mm})$ that contained $100 \mathrm{~g}$ sterilized artificial soil. The biocontrol experiments were conducted in triplicate (20 seedlings for each treatment) in an artificial climate chambers $\left(25^{\circ} \mathrm{C} / 18^{\circ} \mathrm{C}\right.$ day/night temperatures, 3500 Lux light for 16 $\mathrm{h} / \mathrm{d}$, and $80 \%$ relative humidity).

For the biocontrol assay of root rot disease, $20 \mathrm{~mL}$ cell suspension $\left(1.0 \times 10^{8} \mathrm{cfu} \mathrm{ml}^{-1}\right)$ of B. subtilis 3610 or its derivatives, with or without $0.5 \%(\mathrm{w} / \mathrm{v})$ sucrose, was poured into each pot. $6 \mathrm{~h}$ later, $20 \mathrm{~mL}$ conidial suspension $(5.0 \times$ $10^{6} \mathrm{cfu} \mathrm{\textrm {mL } ^ { - 1 }}$ ) of Fusarium oxysporum f. sp. Lycopersici was poured into each pot. The disease control efficacy was surveyed and calculated according to a published protocol [75]. For the biocontrol assay of gray mold disease, $48 \mathrm{~h}$ after tomato seedling transplantation and treatment by B. subtilis cell suspension, $2 \mathrm{~mL}$ conidial suspension of Botrytis cinereal $\left(1.0 \times 10^{5} \mathrm{cfu} \mathrm{mL}^{-1}\right)$ was sprayed to every seedling. The disease control efficacy was surveyed and calculated accordingly [76].

\section{Solid surface motility (SSM)}

Cells were grown overnight at $37^{\circ} \mathrm{C}$ in LB broth. Solid LB plates $(1.5 \%$ agar, w/v) supplemented with sugars were 
freshly prepared and dried for $30 \mathrm{~min}$ in a laminar flow hood prior to use. $2 \mu \mathrm{L}$ cell suspension was inoculated onto the plate, dried for $5 \mathrm{~min}$ on bench, and incubated at $37^{\circ} \mathrm{C}$ for $8-12 \mathrm{~h}$ with the plates facing upside down. Each data point represents an average from three independent experiments. Flagellum staining of the cells collected from the plates for SSM was performed as described previously [77].

To determine the influence of exogenous chemical compounds on SSM by B. subtilis, pure chemicals were supplemented to the SLB plates as indicated. Surfactin was dissolved in $100 \%$ methanol at the stock concentration of $180 \mathrm{mg} / \mathrm{mL}$. $10 \mu \mathrm{L}$ of the surfactin stock solution was added into an oxford cup $1 \mathrm{~cm}$ away from the center of the plate. Other chemical compounds were dissolved in sterile water at the concentration of $20 \mathrm{mg} / \mathrm{mL}$. Then, $100 \mu \mathrm{L}$ stock solution with the indicated concentration was added into LB medium and dried for $20 \mathrm{~min}$ in a laminar flow hood.

\section{Soil collection and rhizosphere sampling}

Soil used in plant root microbiome studies were collected from a wheat and maize rotation field in Wen'an County $\left(116.66^{\circ} \mathrm{E}\right.$ and $\left.38.93^{\circ} \mathrm{N}\right)$, Hebei Province, China. The field soil was collected on June 14, 2019, prior to the wheat harvest and maize seeding when the diversity and richness of the soil microbial community was high. Tomato cultivar (Zhongza 9) was grown in this natural soil and inoculated with the wild type or the $s a c B$ deletion mutant of $B$. subtilis 3610 and supplemented with or without sucrose. Tomato seedlings were grown in square PVC pots $(70 \mathrm{~mm} \times 70 \mathrm{~mm} \times 75 \mathrm{~mm})$ containing $100 \mathrm{~g}$ soil, with an initial moisture content of $30 \%$ (v/w). During the 25-day period, tomatoes were grown in the moisture chamber as described above. Subsequently, the experimental treatments contained: (1) inoculation of WT $B$. subtilis or (2) $\Delta s a c B$ mutant without sugar supplementation; (3) inoculation of WT B. subtilis or (4) $\Delta s a c B$ mutant with sucrose supplementation; (5) with sucrose supplementation but no bacteria; (6) without sucrose supplementation and no bacteria as a negative control. For the treatments, overnight cultivated bacterial suspensions $\left(1.0 \times 10^{8}\right.$ cells $/ \mathrm{mL}, 5 \mathrm{~mL}$ per pot $)$ and $/$ or $73 \mathrm{mM}$ sucrose $(10 \mathrm{~mL}$ per pot) were dripped slowly into the soil surrounding the plant root, and water $(15 \mathrm{~mL}$ per pot) as the negative control. For all treatments, the experiment was performed in three biological replicates (10 tomato plants per replicate). After another 10 days of incubation, rhizosphere soil samples were obtained. To do so, the plant was uprooted by scoop and loosely adhering soil was removed by shaking vigorously. The tightly adhering soil around the root, regarded as rhizosphere soil, was placed in a sterilized $50 \mathrm{~mL}$ Falcon tube and visible plant roots were removed carefully from each sample. Rhizosphere samples were stored at $-80^{\circ} \mathrm{C}$ for further use.

\section{Statistical analyses}

Statistical analysis was performed using SPSS software version 20.0 (SPSS Inc., Chicago, IL, USA). Comparisons were done using one-way analysis of variance, followed by Tukey post-tests (set at 5\%) which correct for multiple comparisons using statistical hypothesis testing. Means of different treatments were compared using the least significant difference (LSD) at a $0.05(*)$ or $0.01(* *)$ level of probability. The letters above the columns indicate statistically significant differences based on Student's $t$ test (the capital letters: $p<0.01$; the lower letters: $P<0.05$ ). The Pearson correlation coefficient was analyzed using doublevariable analysis. All error bars show the mean and standard deviation (SD). Each experimental treatment had three biological replicates.

The following assays were described in Supplementary Methods:

(1) 16S rRNA gene MiSeq sequencing and sequencing analyses.

(2) Microscopic analysis, including laser scanning confocal microscopy, light microscopy, and photography.

(3) Assays of surfactin production by HPLC.

(4) Assays of $\beta$-galactosidase activities.

(5) Quantification of cell fluorescence intensity.

Acknowledgements We thank Dr. P. Ma, Hebei Academy of Agriculture and Forestry Sciences, for providing the B. subtilis Strain NCD-2 and the srfAA mutant. The research in the Tian laboratory was supported by grants from the National Key R\&D Program of China (2017YFD0201101), the Key Technology R\&D Program of Tianjin (17YFZCNC00430), and Creative Research for Young Scientists of Tianjin Academy of Agricultural Sciences (China) (2020001). The research in the Chai laboratory was supported by a grant from the US National Science Foundation (MCB 1651732). TT was supported by a fellowship from the China Scholarship Council (201809120002) to study abroad at Northeastern University.

Author contributions TT and BS performed the bacterial motility experiments and the strain construction; HS, BS, and XL performed bacterial colonization experiments, and the metagenome analysis; YLiu performed bacterial colonization assay; LZ, SL, and YLi performed the HPLC analysis and biocontrol experiments; TG, performed competitive co-culture experiments; $\mathrm{YH}$ performed $\beta$-galactosidase activity assay; TT, YC, and QW designed the study, and wrote the paper.

\section{Compliance with ethical standards}

Conflict of interest The authors declare no competing interests. 
Publisher's note Springer Nature remains neutral with regard to jurisdictional claims in published maps and institutional affiliations.

Open Access This article is licensed under a Creative Commons Attribution 4.0 International License, which permits use, sharing, adaptation, distribution and reproduction in any medium or format, as long as you give appropriate credit to the original author(s) and the source, provide a link to the Creative Commons license, and indicate if changes were made. The images or other third party material in this article are included in the article's Creative Commons license, unless indicated otherwise in a credit line to the material. If material is not included in the article's Creative Commons license and your intended use is not permitted by statutory regulation or exceeds the permitted use, you will need to obtain permission directly from the copyright holder. To view a copy of this license, visit http://creativecommons. org/licenses/by/4.0/.

\section{References}

1. Radhakrishnan R, Hashem A, Abd Allah EF. Bacillus: a biological tool for crop improvement through bio-molecular changes in adverse environments. Front Physiol. 2017;8:667-81.

2. Santoyo G, Orozco-Mosqueda MDC, Govindappa M. Mechanisms of biocontrol and plant growth-promoting activity in soil bacterial species of Bacillus and Pseudomonas: a review. Biocontrol Sci Technol. 2012;22:855-72.

3. Kolter R, Greenberg EP. Microbial sciences: the superficial life of microbes. Nature. 2006;441:300-2.

4. Beauregard PB, Chai Y, Vlamakis H, Losick R, Kolter R. Bacillus subtilis biofilm induction by plant polysaccharides. Proc Nat Acad Sci USA. 2013;110:E1621-30. https://doi.org/10.1073/pnas. 1218984110.

5. Chen Y, Shugeng C, Yunrong C, Jon C, Roberto K, Jian-Hua G, et al. A Bacillus subtilis sensor kinase involved in triggering biofilm formation on the roots of tomato plants. Mol Microbiol. 2012;85:418-30.

6. Rudrappa T, Czymmek KJ, Paré PW, Bais HP. Root-secreted malic acid recruits beneficial soil bacteria. Plant Physiol. 2008; $148: 1547-56$

7. Hall Stoodley L, Costerton JW, Stoodley P. Bacterial biofilms: from the natural environment to infectious diseases. Nat Rev Microbiol. 2004;2:95-108.

8. Hirsch PR, Miller AJ, Dennis PG. Molecular microbial ecology of the rhizosphere $\mathrm{Ch}$. Do root exudates exert more influence on rhizosphere bacterial community structure than other rhizodeposits? New Jersey: Wiley Press; 2013. p. 229-42.

9. Nguyen C. Rhizodeposition of organic $\mathrm{C}$ by plant: mechanisms and controls. Agronomie. 2003;23:375-96.

10. Mendes R, Marco K, Irene DB, Ester D, Menno VDV, Schneider JHM, et al. Deciphering the rhizosphere microbiome for diseasesuppressive bacteria. Science. 2011;332:1097-1100.

11. Edwards J, Cameron J, Christian SM, Eugene L, Natraj Kumar P, Srijak B, et al. Structure, variation, and assembly of the rootassociated microbiomes of rice. Proc Nat Acad Sci USA. 2015;112:E911-20.

12. Durán P, Tortella G, Viscardi S, Barra PJ, Carrión VJ, Mora MdlL, et al. Microbial community composition in take-all suppressive soils. Front Microbiol. 2018;9:1-15. https://doi.org/10. 3389/fmicb.2018.02198.

13. Raaijmakers JM, Mazzola M. Ecology. Soil immune responses. Science. 2016;352:1392-3.

14. Zhalnina K, Louie KB, Zhao H, Mansoori N, Rocha UND, Shi S, et al. Dynamic root exudate chemistry and microbial substrate preferences drive patterns in rhizosphere microbial community assembly. Nat Microbiol. 2018;3:470-80.
15. Dennis PG, Miller AJ, Hirsch PR. Are root exudates more important than other sources of rhizodeposits in structuring rhizosphere bacterial communities? FEMS Microbiol Ecol. 2010;72:313-27.

16. Bais HP, Weir TL, L G, Gilroy S, Vivanco JM. The role of root exudates in rhizosphere interactions with plants and other organisms. Annu Rev Plant Biol. 2006;57:233-66.

17. Lugtenberg B, Kamilova F. Plant-growth-promoting rhizobacteria. Annu Rev Microbiol. 2009;63:541-56.

18. Claessen D, Rozen DE, Kuipers OP, Lotte S-A, van Wezel GP. Bacterial solutions to multicellularity: a tale of biofilms, filaments and fruiting bodies. Nat Rev Microbiol. 2014;12:115-24.

19. Yaryura PM, León M, Correa OS, Kerber NL, Pucheu NL, García AF. Assessment of the role of chemotaxis and biofilm formation as requirements for colonization of roots and seeds of soybean plants by Bacillus amyloliquefaciens BNM339. Curr Microbiol. 2008;56:625-32.

20. Allard-Massicotte R, Tessier L, Lécuyer F, Lakshmanan V, Lucier J-F, Garneau D, et al. Bacillus subtilis early colonization of Arabidopsis thaliana roots involves multiple chemotaxis receptors. mBio. 2016;7:e1664-16. https://doi.org/10.1128/mBio. 01664-16.

21. Patrick JE, Kearns DB. Swarming motility and the control of master regulators of flagellar biosynthesis. Mol Microbiol. 2012;83:14-23.

22. Partridge JD, Harshey RM. Swarming: flexible roaming plans. J Bacteriol. 2013;195:909-18.

23. Grau RR, De OaP, Kunert M, Leã Ini C, Gallegos-Monterrosa R, Mhatre E, et al. A duo of potassium-responsive histidine kinases govern the multicellular destiny of Bacillus subtilis. mBio. 2015;6:e00581.

24. van Gestel J, Vlamakis H, Kolter R. From cell differentiation to cell collectives: Bacillus subtilis uses division of labor to migrate. PLoS Biol. 2015;13:e1002141. https://doi.org/10.1371/journal. pbio.1002141.

25. Harshey RM. Bacterial motility on a surface: many ways to a common goal. Annu Rev Microbiol. 2003;57:249-73.

26. Kearns DB. A field guide to bacterial swarming motility. Nat Rev Microbiol. 2010;8:634-44.

27. Fan H, Zhang Z, Yan L, Xun Z, Duan Y, Qi W. Biocontrol of bacterial fruit blotch by Bacillus subtilis 9407 via surfactinmediated antibacterial activity and colonization. Front Microbiol. 2017;8:1973-88.

28. Gao S, Wu H, Yu X, Qian L, Gao X. Swarming motility plays the major role in migration during tomato root colonization by Bacillus subtilis SWR01. Biol Control. 2016;98:11-7.

29. Harshey RM, Partridge JD. Shelter in a swarm. J Mol Biol. 2015;427:3683-94.

30. Kawagishi I, Imagawa M, Imae Y, Mccarter L, Homma M. The sodium-driven polar flagellar motor of marine Vibrio as the mechanosensor that regulates lateral flagellar expression. Mol Microbiol. 1996;20:693-9.

31. Belas R, Suvanasuthi R. The ability of Proteus mirabilis to sense surfaces and regulate virulence gene expression involves FliL, a flagellar basal body protein. J Bacteriol. 2005;187:6789-803.

32. Shi S, Richardson AE, Maureen OC, Deangelis KM, Jones EE, Alison S, et al. Effects of selected root exudate components on soil bacterial communities. FEMS Microbiol Ecol. 2011; 77:600-10

33. Lemoine R, La CS, Atanassova R, Dédaldéchamp F, Allario T, Pourtau N, et al. Source-to-sink transport of sugar and regulation by environmental factors. Front Plant Sci. 2013; 4:272-93.

34. Branda SS, González-Pastor JE, Ben-Yehuda S, Losick R, Kolter R. Fruiting body formation by Bacillus subtilis. Proc Nat Acad Sci USA. 2001;98:11621-6. 
35. Russell DW, Sambrook J. Molecular cloning: a laboratory manual. Cold Spring Harbor: Cold Spring Harbor Laboratory Press; 2001.

36. Ongena M, Jacques P. Bacillus lipopeptides: versatile weapons for plant disease biocontrol. Trends Microbiol. 2008;16:115-25.

37. Nakano MM, Marahiel MA, Zuber P. Identification of a genetic locus required for biosynthesis of the lipopeptide antibiotic surfactin in Bacillus subtilis. J Bacteriol. 1988;170:5662-8. https:// doi.org/10.1128/jb.170.12.5662-5668.1988.

38. Delange RJ, Chang JY, Shaper JH, Martinez RJ, Komatsu SK, Glazer AN. On the amino-acid sequence of flagellin from Bacillus subtilis 168: comparison with other bacterial flagellins. Proc Natl Acad Sci USA. 1973;70:3428-31.

39. Ghelardi E, Salvetti S, Ceragioli M, Gueye SA, Celandroni F, Senesi S. Contribution of surfactin and SwrA to flagellin expression, swimming, and surface motility in Bacillus subtilis. Appl Environ Microbiol. 2012;78:6540. https://doi.org/10.1128/ AEM.01341-12.

40. Singh AK, Rautela R, Cameotra SS. Substrate dependent in vitro antifungal activity of Bacillus sp strain AR2. Micro Cell Fact. 2014;13:67. https://doi.org/10.1186/1475-2859-13-67.

41. Fouet A, Klier A, Rapoport G. Nucleotide sequence of the sucrase gene of Bacillus subtilis. Gene. 1986;45:221-5. https://doi.org/10. 1016/0378-1119(86)90258-1.

42. Pelicic V, Reyrat JM, Gicquel B. Expression of the Bacillus subtilis $s a c B$ gene confers sucrose sensitivity on mycobacteria. $\mathrm{J}$ Bacteriol. 1996;178:1197-9. https://doi.org/10.1128/jb.178.4. 1197-1199.1996.

43. Gay P, Le Coq D, Steinmetz M, Ferrari E, Hoch JA. Cloning structural gene $s a c B$, which codes for exoenzyme levansucrase of Bacillus subtilis: expression of the gene in Escherichia coli. J Bacteriol. 1983;153:1424-31.

44. Öner ET, Hernández L, Combie J. Review of levan polysaccharide: From a century of past experiences to future prospects. Biotechnol Adv. 2016;34:827-44.

45. Pereira Y, Petit-Glatron M-F, Chambert R. yveB, encoding endolevanase LevB, is part of the $s a c B-y v e B-y v e A$ levansucrase tricistronic operon in Bacillus subtilis. Microbiology. 2001;147:3413-9. https://doi.org/10.1099/00221287-147-12-3413.

46. Ding H, Niu B, Fan H, Li Y, Wang Q. Draft genome sequence of Bacillus cereus 905, a plant growth-promoting rhizobacterium of wheat. Genome Announc. 2016;4:e00489-16.

47. Kuzyakov Y, Domanski G. Carbon input by plants into the soil. Rev J Plant Nutr Soil Sci. 2000;163:421-31.

48. Srivastava ACD, Kasturi, Ajieren E, Costilla G, Mcgarry RC, Ayre BG. Arabidopsis plants harbouring a mutation in AtSUC2, encoding the predominant sucrose/proton symporter necessary for efficient phloem transport, are able to complete their life cycle and produce viable seed. Ann Bot. 2009;104:1121-8.

49. Durand M, Mainson D, Porcheron B, Maurousset L, Lemoine R, Pourtau N. Carbon source-sink relationship in Arabidopsis thaliana: the role of sucrose transporters. Planta. 2018;247:587-611.

50. Meyer S, Sauer N. Wounding enhances expression of AtSUC3, a sucrose transporter from Arabidopsis sieve elements and sink tissues. Plant Physiol. 2004;134:684-93.

51. Cordoba E, Aceveszamudio DL, Hernándezbernal AF, Ramosvega M, León P. Sugar regulation of Sugar Transporter Protein 1 (STP1) expression in Arabidopsis thaliana. J Exp Bot. 2015;66:147-59.

52. Alonso JM, Stepanova AN, Leisse TJ, Kim CJ, Huaming C, Paul $\mathrm{S}$, et al. Genome-wide insertional mutagenesis of Arabidopsis thaliana. Science. 2003;301:653-7.

53. v. Lippmann EO. Ueber das Lävulan, eine neue, in der Melasse der Rubenzuckerfabriken vorkommende Gummiart. Chemisches Cent B1. 1881;14:669-71.
54. Greigsmith R. The gum fermentation of sugar cane juice. Proc Linn Soc N S W. 1902;26:589-625.

55. Berendsen RL, Pieterse CMJ, Bakker PAHM. The rhizosphere microbiome and plant health. Trends Plant Sci. 2012;17:478-86. https://doi.org/10.1016/j.tplants.2012.04.001.

56. Wheatley RM, Poole PS. Mechanisms of bacterial attachment to roots. FEMS Microbiol Rev. 2018;42:448-61. https://doi.org/10. 1093/femsre/fuy014.

57. Lugtenberg BJ, Dekkers L, Bloemberg GV. Molecular determinants of rhizosphere colonization by Pseudomonas. Annu Rev Phytopathol. 2001;39:461-90. https://doi.org/10.1146/annurev. phyto.39.1.461.

58. Cole BJ, Feltcher ME, Waters RJ, Wetmore KM, Mucyn TS, Ryan EM, et al. Genome-wide identification of bacterial plant colonization genes. PLOS Biol. 2017;15:e2002860. https://doi. org/10.1371/journal.pbio.2002860.

59. Tian T, Reverdy A, She Q, Sun B, Chai Y. The role of rhizodeposits in shaping rhizomicrobiome. Environ Microbiol Rep. 2020;12:160-72. https://doi.org/10.1111/1758-2229.12816.

60. Ward JM, Kühn C, Tegeder M, Frommer WB. Sucrose transport in higher plants. Int Rev Cytol. 1998;178:41-71. https://doi.org/ 10.1016/s0074-7696(08)62135-x.

61. Jaeger CH 3rd, Lindow SE, Miller W, Clark E, Firestone MK. Mapping of sugar and amino acid availability in soil around roots with bacterial sensors of sucrose and tryptophan. Appl Environ Microbiol. 1999;65:2685-90.

62. Fatima U, Senthil-Kumar M. Plant and pathogen nutrient acquisition strategies. Front Plant Sci. 2015;6:750. https://doi.org/10. 3389/fpls.2015.00750.

63. Ratnayake M, Leonard RT, Menge JA. Root exudation in relation to supply of phosphorus and its possible relevance to Mycorrhizal formation. N Phytol. 1978;81:543-52. https://doi.org/10.1111/j. 1469-8137.1978.tb01627.x.

64. Bais HP, Fall R, Vivanco JM. Biocontrol of Bacillus subtilis against infection of Arabidopsis roots by Pseudomonas syringae is facilitated by biofilm formation and surfactin production. Plant Physiol. 2004;134:307-19. https://doi.org/10.1104/pp.103.028712.

65. Wadhams GH, Armitage JP. Making sense of it all: bacterial chemotaxis. Nat Rev Mol Cell Biol. 2004;5:1024-37. https://doi. org/10.1038/nrm1524.

66. Thérien M, Kiesewalter HT, Auria E, Charron-Lamoureux V, Wibowo M, Maróti G, et al. Surfactin production is not essential for pellicle and root-associated biofilm development of Bacillus subtilis. Biofilm. 2020;2:100021. https://doi.org/10.1016/j.bioflm. 2020.100021.

67. Dogsa I, Brloznik M, Stopar D, Mandic Mulec I. Exopolymer diversity and the role of levan in Bacillus subtilis biofilms. PLoS ONE. 2013;8:e62044.

68. Bezzate S, Aymerich S, Chambert R, Czarnes S, Berge O, Heulin T. Disruption of the Paenibacillus polymyxa levansucrase gene impairs its ability to aggregate soil in the wheat rhizosphere. Environ Microbiol. 2000;2:333-42. https://doi.org/10.1046/j. 1462-2920.2000.00114.x.

69. Yuan J, Wen T, Zhang H, Zhao M, Penton CR, Thomashow LS, et al. Predicting disease occurrence with high accuracy based on soil macroecological patterns of Fusarium wilt. ISME J. 2020;14:2936-50. https://doi.org/10.1038/s41396-020-0720-5.

70. Cha J-Y, Han S, Hong H-J, Cho H, Kim D, Kwon Y, et al. Microbial and biochemical basis of a Fusarium wilt-suppressive soil. ISME J. 2016;10:119-29. https://doi.org/10.1038/ismej. 2015.95.

71. Chowdhury SP, Hartmann A, Gao XW, Borriss R. Biocontrol mechanism by root-associated Bacillus amyloliquefaciens FZB42 a review. Front Microbiol. 2015;6:780-91.

72. Ben-Jabeur M, Ghabri E, Myriam M, Hamada W. Thyme essential oil as a defense inducer of tomato against gray mold and 
Fusarium wilt. Plant Physiol Biochem. 2015;94:35-40. https:// doi.org/10.1016/j.plaphy.2015.05.006.

73. Greenwich J, Reverdy A, Gozzi K, Di Cecco G, Tashjian T, Godoy-Carter V, et al. A decrease in serine levels during growth transition triggers biofilm formation in Bacillus subtilis. J Bacteriol. 2019;201:e00155-19. https://doi.org/10.1128/JB.00155-19.

74. Greene EA, Spiegelman GB. The Spo0A protein of Bacillus subtilis inhibits transcription of the $a b r B$ gene without preventing binding of the polymerase to the promoter. J Biol Chem. 1996;271:11455-61.
75. Liu Y, Chen Z, Liang X, Zhu J. Screening, evaluation and identification of antagonistic bacteria against Fusarium oxysporum $\mathrm{f}$. sp. lycopersici and Ralstonia solanacearum. Chin J Biol Control. 2012;28:101-8.

76. Qiao J, Zhang X, Liang X, Liu Y, Liu Y. Plant system resistance triggered by root-colonizing Bacillus subtilis PTS-394 and its control effect on tomato gray mold. Chin J Biol Control. 2017;33:219-25.

77. Blenden DC, Goldberg HS. Silver impregnation stain for leptospira and flagella. J Bacteriol. 1965;89:899-900. 